\title{
Conformational Studies on Five Octasaccharides Isolated from Chondroitin Sulfate Using NMR Spectroscopy and Molecular Modeling ${ }^{\dagger}$
}

\author{
Véronique Blanchard, ${ }^{\ddagger}$ Franck Chevalier ${ }^{\S}$ Anne Imberty, ${ }^{\S}$ Bas R. Leeflang, ${ }^{\ddagger}$ Basappa, ${ }^{I I \perp}$ Kazuyuki Sugahara, ${ }^{*, l, \perp}$ and \\ Johannis P. Kamerling*, \\ Bijvoet Center, Department of Bio-Organic Chemistry, Utrecht University, Padualaan 8, NL-3584 CH Utrecht, The Netherlands, \\ CERMAV-CNRS, Université Joseph Fourier, BP53, F-38041 Grenoble Cedex 09, France, and Department of Biochemistry, \\ Kobe Pharmaceutical University, 4-19-1 Motoyamakita-machi, Higashinada-ku, Kobe 658-8558, Japan
}

Received September 22, 2006; Revised Manuscript Received November 21, 2006

\begin{abstract}
Chondroitin sulfate proteoglycans (CS-PG) are involved in the regulation of the central nervous system in vertebrates due to their presence on cell surfaces and in the extracellular matrix of tissues. The CS moieties are built up from repeating -4$) \operatorname{GlcA}(\beta 1-3) \operatorname{GalNAc}(\beta 1-$ disaccharide units, partly O-sulfated at different positions. The presence of the disulfated disaccharide D-unit, GlcA2S( $\beta 1-3)$ GalNAc6S, in the CS moiety of the proteoglycan DSD-1-PG/phosphacan, correlates with neurite outgrowth promotion. The binding of monoclonal antibody $(\mathrm{mAb})$ 473HD to DSD-1-PG, reducing neuronal stimulation, is inhibited by shark cartilage CS-D. CS-D is also recognized by two other mAbs, MO-225 and CS-56. Conformational studies were performed using NMR spectroscopy and molecular modeling on five octasaccharides isolated from shark cartilage CS-D. These octasaccharides present different binding properties toward the three mAbs. The combination of the experimental and theoretical approaches revealed that the sulfate group at position 2 of GlcA in disaccharide D and the presence of an exocyclic negative tail in disaccharides $\mathrm{C}[\mathrm{GlcA}(\beta 1-3) \mathrm{GalNAc6} S]$ and $\Delta \mathrm{C}\left[\Delta^{4,5} \mathrm{Hex} \mathrm{A}(\alpha 1-3) \mathrm{GalNAc} 6 S\right]$ are important for antibody recognition.
\end{abstract}

Chondroitin sulfate (CS), ${ }^{1}$ as well as dermatan sulfate and heparan sulfate, consists of linear glycosaminoglycan (GAG) side chains attached to the protein backbone in proteoglycans (PGs). The CS GAGs are built up from partly O-sulfated repeating -4$) \operatorname{GlcA}(\beta 1-3) \operatorname{GalNAc}(\beta 1-$ disaccharide units. The CS isoforms differ in the degree and position of the $O$-sulfate groups, the disaccharides A $[\mathrm{GlcA}(\beta 1-3) \mathrm{GalNAc} 4 S$ ] and $\mathrm{C}[\mathrm{GlcA}(\beta 1-3) \mathrm{GalNAc} 6 S]$ being the major constituents of mammalian CS chains.

PGs are located on the surface of cells and in the extracellular matrix in many organs. CS-PGs are the most abundant type of PGs found in the central nervous system (CNS). PGs play a crucial role as neurite growth promoters in neural development (for reviews, see refs 1-3) and in

$\dagger$ This research has been financially supported by the Council for Chemical Sciences of the Netherlands Organization for Scientific Research (CW-NWO), the Human Frontier Science Program (K.S.), and the Core Research for Evolutional Science and Technology of the Japan Science and Technology Agency (K.S.).

* To whom correspondence should be addressed: e-mail j.p.kamerling@chem.uu.nl or k-sugar@sci.hokudai.ac.jp.

$\doteqdot$ Utrecht University.

$\S$ CERMAV-CNRS.

"Kobe Pharmaceutical University.

$\perp$ Present address: Frontier Research Center for Post-Genomic Science and Technology, Faculty of Advanced Life Science, Graduate School of Life Science, Hokkaido University, Sapporo 001-0021, Japan.

${ }^{1}$ Abbreviations: $\Delta^{4,5} \mathrm{HexA}, 4$-deoxy-L-threo-hex-4-enopyranuronic acid; CNS, central nervous system; CS, chondroitin sulfate; DS, dermatan sulfate; GAG, glycosaminoglycan; mAb, monoclonal antibody; MLEV, composite pulse devised by M. Levitt; NMR, nuclear magnetic resonance; NOESY, nuclear Overhauser effect spectroscopy; PG, proteoglycan; TOCSY, total correlation spectroscopy. neuronal plasticity by forming perineuronal nets around synapses $(4,5)$. In addition, in vitro assays have shown that some CS-PGs act as barriers to axon regeneration after a CNS injury $(6,7)$, whereby the inhibitory activity was mostly associated to the carbohydrate moiety, as treatment with chondroitinase $\mathrm{ABC}$ led to a significant increase of neurite length $(8,9)$. Chondroitinase $\mathrm{ABC}$ degrades $\mathrm{CS}$ via a $\beta$-eliminative cleavage at internal GlcA residues, yielding $\Delta^{4,5} \mathrm{HexA}$-containing oligosaccharides $\left(\Delta^{4,5} \mathrm{HexA}=4\right.$-deoxyL-threo-hex-4-enopyranuronic acid) (10).

The CS-PG named DSD-1-PG, located on the surface of immature glial cells in the CNS in developing mouse brain, promotes neurite outgrowth (11). The disulfated disaccharide $\mathrm{D}[\mathrm{GlcA} 2 S(\beta 1-3)$ GalNAc6S] (Figure 1), being the major component in shark cartilage CS-D, is also present in some neurotrophic CS-PGs such as DSD-1-PG (12). Monoclonal antibody $(\mathrm{mAb}) 473 \mathrm{HD}$, which recognizes an epitope of DSD-1-PG, strongly reduces neurite outgrowth stimulation. Interestingly, shark cartilage CS-D inhibits the binding of $\mathrm{mAb} 473 \mathrm{HD}$ to the DSD-1-PG epitope (13). CS-D is also preferentially recognized by two other mAbs raised against CS used for immunohistochemical studies, namely, CS-56 (14) and MO-225 (15). Additional studies have suggested that the CS-56 and MO-225 epitopes are also involved in neuritogenesis (16). Some oligosaccharides isolated after chondroitinase $\mathrm{ABC}$ digestion of a shark cartilage CS-D isoform (13) are recognized by the mAbs 473HD, CS-56, and MO-225 (17). Hexasaccharides and longer oligosaccharides containing the sequences $\mathrm{A}-\mathrm{D}$ and/or $\mathrm{D}-\mathrm{A}$ (Figure 1) appear to be required for the effective binding of $\mathrm{mAb}$ 

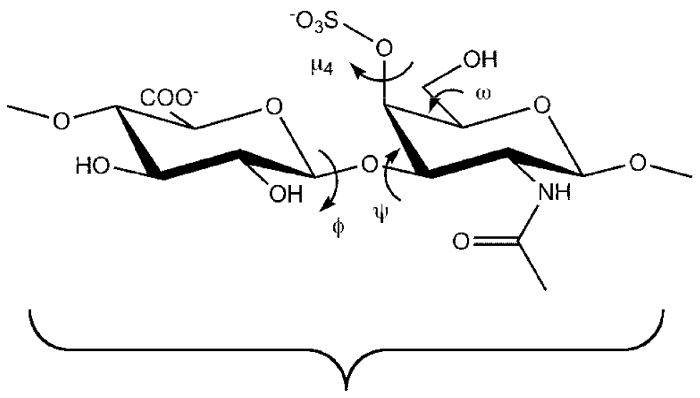

A

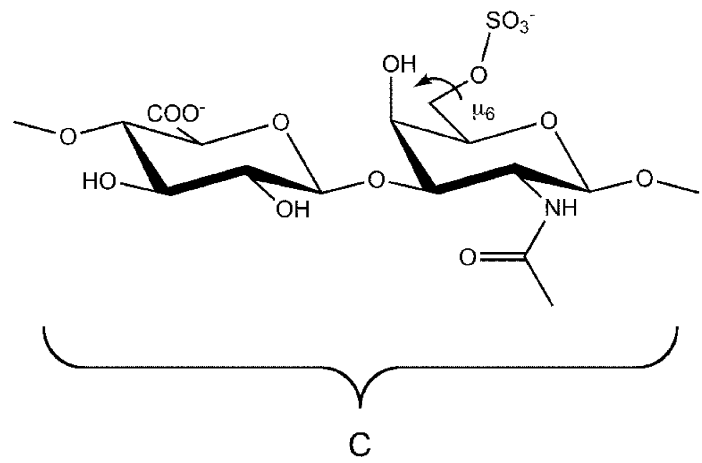

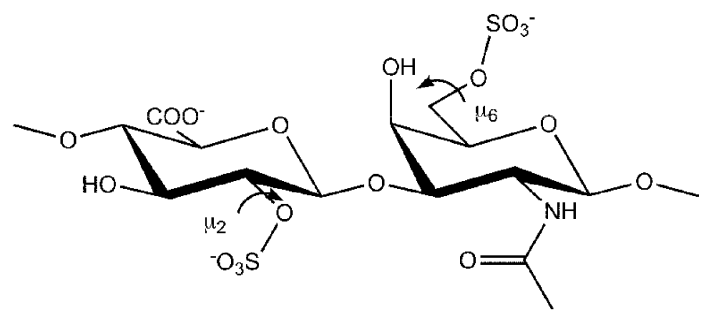

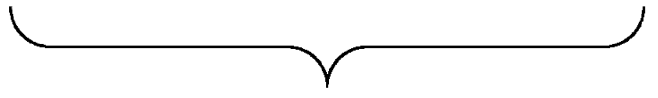

D

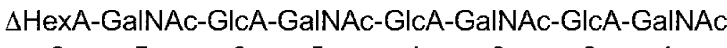

$\begin{array}{llllllll}8 & 7 & 6 & 5 & 4 & 3 & 2 & 1\end{array}$

FIGURE 1: Schematic representation of the repeating units A, C, and D together with the labeling of the torsion angles of interest.

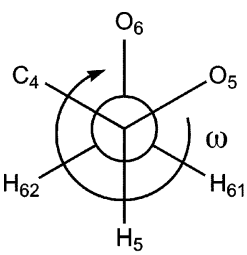

(a)

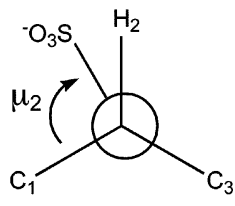

(b)

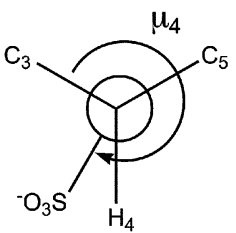

(c)

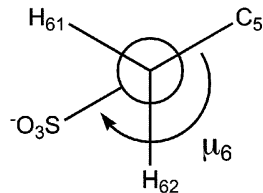

(d)

FIGURE 2: Newman projections showing the torsional angles of interest: (a) $\omega$; (b) $\mu_{2}$; (c) $\mu_{4}$; (d) $\mu_{6}$ (see Figure 1).

473HD. MAb CS-56 binds octasaccharides with the following preference, $\Delta \mathrm{C}-\underline{\mathrm{A}-\mathrm{D}-\mathrm{C}}>\Delta \mathrm{A}-\underline{\mathrm{A}-\mathrm{D}-\mathrm{C}}>\Delta \mathrm{A}-\underline{\mathrm{A}-\mathrm{D}-\mathrm{A}}>$ $\triangle \mathrm{C}$-A-D-A, whereas mAb MO-225 reacts differently toward the four positive octasaccharides, $\triangle \mathrm{C}-\mathrm{A}-\mathrm{D}-\mathrm{C}>\Delta \mathrm{C}-\mathrm{A}-\mathrm{D}-\mathrm{A}$ $>\Delta \mathrm{A}-\mathrm{A}-\mathrm{D}-\mathrm{C}>\Delta$-A-A-D-A. In this coding system $\Delta$ denotes the presence of $\Delta^{4,5} \mathrm{HexA}$ in the specific terminal disaccharide element. None of the mAbs reacts with $\Delta \mathrm{C}$ $\mathrm{C}-\mathrm{C}-\mathrm{C}$.

Here, we present a structural study of the five octasaccharides $\Delta \mathrm{C}$-A-D-C, $\Delta \mathrm{A}-\mathrm{A}-\mathrm{D}-\mathrm{C}, \Delta \mathrm{A}-\mathrm{A}-\mathrm{D}-\mathrm{A}, \Delta \mathrm{C}-\mathrm{A}-\mathrm{D}-\mathrm{A}$, and $\triangle \mathrm{C}-\mathrm{C}-\mathrm{C}-\mathrm{C}$ using NMR spectrosocopy and molecular modeling, with the aim to explain their reactivity against the three mAbs.

\section{EXPERIMENTAL PROCEDURES}

Materials. The isolation of octasaccharide $\Delta^{4,5} \mathrm{HexA}(\alpha 1-$ $3)$ GalNAc $6 S(\beta 1-4) \mathrm{GlcA}(\beta 1-3) \mathrm{GalNAc} 4 S(\beta 1-4)$ $\operatorname{GlcA} 2 S(\beta 1-3) \operatorname{GalNAc6S}(\beta 1-4) \operatorname{GlcA}(\beta 1-3) \operatorname{GalNAc} 6 S(\Delta \mathrm{C}$ A-D-C) from shark cartilage CS-D has been described previously (13).

For the molecular modeling five related octasaccharides were chosen: $\Delta \mathrm{C}-\mathrm{A}-\mathrm{D}-\mathrm{C}, \Delta^{4,5} \operatorname{HexA}(\alpha 1-3)$ GalNAc6 $S(\beta 1-$ $4) \mathrm{GlcA}(\beta 1-3) \mathrm{GalNAc} 4 S(\beta 1-4) \mathrm{GlcA} 2 S(\beta 1-3) \mathrm{GalNAc} 6 S$ $(\beta 1-4) \mathrm{GlcA}(\beta 1-3)$ GalNAc $6 S ; \quad \Delta \mathrm{A}-\mathrm{A}-\mathrm{D}-\mathrm{C}, \quad \Delta^{4,5} \mathrm{HexA}-$ $(\alpha 1-3)$ GalNAc $4 S(\beta 1-4) \operatorname{GlcA}(\beta 1-3)$ GalNAc $4 S(\beta 1-4)$ GlcA2S( $\beta 1-3)$ GalNAc6S $(\beta 1-4) \operatorname{GlcA}(\beta 1-3)$ GalNAc $6 S ; \Delta$ AA-D-A,$\quad \Delta^{4,5} \operatorname{HexA}(\alpha 1-3) \operatorname{GalNAc} 4 S(\beta 1-4) \operatorname{GlcA}(\beta 1-3)$ -
GalNAc4S( $\beta 1-4)$ GlcA $2 S(\beta 1-3)$ GalNAc6S( $\beta 1-4)$ GlcA$(\beta 1-3)$ GalNAc4S; $\Delta$ C-A-D-A, $\Delta^{4,5} \mathrm{HexA}(\alpha 1-3)$ GalNAc6 $S(\beta 1-$ $4) \mathrm{GlcA}(\beta 1-3) \mathrm{GalNAc} 4 S(\beta 1-4) \mathrm{GlcA} 2 S(\beta 1-3)$ GalNAc6 $S$ $(\beta 1-4) \mathrm{GlcA}(\beta 1-3) \mathrm{GalNAc} 4 S ; \Delta \mathrm{C}-\mathrm{C}-\mathrm{C}-\mathrm{C}, \Delta^{4,5} \mathrm{HexA}(\alpha 1-$ 3) GalNAc6S $(\beta 1-4) \operatorname{GlcA}(\beta 1-3) \operatorname{GalNAc} 6 S(\beta 1-4) \operatorname{GlcA}(\beta 1-$ 3) GalNAc6S $(\beta 1-4) \operatorname{GlcA}(\beta 1-3)$ GalNAc6 $S$.

Nomenclature. Representations of the disaccharides A, C, and $\mathrm{D}$ are given in Figure 1, along with the labeling of the atoms and the torsion angles of interest; all residues are in the pyranosidic ${ }^{4} C_{1}$ (D) form. The monosaccharide constituents of the studied octasaccharides are numbered from $\mathbf{1}$ to $\mathbf{8}$, independently of the sulfation pattern, residue $\mathbf{8}$ being in all cases $\Delta^{4,5} \operatorname{HexA}$ (Figure 1 ).

The conformations around the $(1 \rightarrow x)$ glycosidic linkages are described by two sets of torsion angles, $\varphi=\mathrm{O}_{5}-\mathrm{C}_{1}-$ $\mathrm{O}_{1}-\mathrm{C}_{x}$ and $\psi=\mathrm{C}_{1}-\mathrm{O}_{1}-\mathrm{C}_{x}-\mathrm{C}_{x+1}$. Other important torsion angles considered are those describing the orientation of the hydroxymethyl group of GalNAc, $\omega=\mathrm{O}_{5}-\mathrm{C}_{5}-\mathrm{C}_{6}-\mathrm{O}_{6}$ (Figure 2a), and the orientation of the $O$-sulfate group at position $x, \mu_{x}=\mathrm{C}_{x-1}-\mathrm{C}_{x}-\mathrm{O}_{x}-\mathrm{S}$ (Figure $2 \mathrm{~b}-\mathrm{d}$ ).

The signs of the torsion angles are in agreement with the recommendations of the IUPAC-IUB Commission of Biochemical Nomenclature (18).

${ }^{1} \mathrm{H}$ NMR Spectroscopy. ${ }^{1} \mathrm{H}$ NMR spectra were recorded using a Micro sample tube (NE-H5/2.5; CortecNet, France) on a Bruker Avance-600 spectrometer, equipped with a 
cryoprobe, or a Bruker Avance-900 spectrometer (Bijvoet Center, Department of NMR Spectroscopy, Utrecht University) at probe temperatures ranging from 277 to $333 \mathrm{~K}$ and at $\mathrm{pH} 7$ (the $\mathrm{pH}$ meter reading has not been corrected for a ${ }^{2} \mathrm{H}$ isotope effect). Samples $(20 \mu \mathrm{g})$ were exchanged three times against $99.9 \%{ }^{2} \mathrm{H}_{2} \mathrm{O}$ (Cambridge Isotope Laboratories Inc., Andover, MA) with intermediate lyophilization and finally dissolved in $0.15 \mathrm{~mL}$ of $99.96 \%{ }^{2} \mathrm{H}_{2} \mathrm{O}$. Chemical shifts $(\delta)$ are expressed in parts per million (ppm) by reference to internal acetone $\left(\delta 2.225\right.$ in $\left.{ }^{2} \mathrm{H}_{2} \mathrm{O}\right)(19)$. In $2 \mathrm{D}$ experiments $\mathrm{H}^{2} \mathrm{HO}$ signal suppression was performed by presaturation of $1 \mathrm{~s}$ during the relaxation delay. 2D-TOCSY spectra were recorded using MLEV-17 mixing sequence cycles of 10, 50, and $100 \mathrm{~ms}$. 2D-NOESY spectra were recorded at $277 \mathrm{~K}$ using a mixing time of $100 \mathrm{~ms}$ and a sweep width of 2600 $\mathrm{Hz}$ in both directions. Spectra were recorded with 2048 complex $t_{2}$ points and 128 complex $t_{1}$ points. NMR data sets were processed and analyzed using in-house developed software packages (J. A. van Kuik, Bijvoet Center, Department of Bio-Organic Chemistry, Utrecht University) with zero filling, $\pi / 2$ shifted sine bell window function for $t_{1}$ and $\pi / 2$ shifted squared sine bell window function for $t_{2}$, and spline baseline correction in both dimensions.

NOESY cross-peak intensities are directly proportional to cross-relaxation rates when mixing times are chosen within the linear region of the initial buildup rate $(<150 \mathrm{~ms})(20)$. Interproton distances $(r)$ are then calculated using the relationship $r_{i j} / r_{0} \approx\left(a_{0} / a_{i j}\right)^{1 / 6}$, whereby the $a$ 's correspond to the cross-peak integrals. The intraresidue distance of 2.5 $\AA$ between GalNAc- $1 \alpha \mathrm{H}-1$ and $\mathrm{H}-2$ was used as a reference for distance calibration (21).

Computational Methods. (A) Molecular Mechanics Calculations. The general molecular mechanics program MM3(92) $(22-24)$ was used to compute the energy of any di- or oligosaccharide conformation. Along with the stretching, bending, dihedral, dipolar, and van der Waals terms, the MM3 force field also includes cross-term effects such as torsion-stretch, torsion-bend, and bend-bend interactions. In addition, it uses an explicit term for hydrogen bonds and takes into account the anomeric and exoanomeric effects (25). The 1992 version includes an angular dependence in the hydrogen-bonding function.

(B) Grid Search. Oligosaccharide conformations depend mainly on the $\varphi$ and $\psi$ torsion angles around the glycosidic linkages. In a first approximation, they can be described by the $(\varphi, \psi)$ potential energy maps of the disaccharide subunits. Taking into account this assumption, adiabatic maps were computed for all of the disaccharides constituting the five octasaccharides $\Delta$ C-A-D-C, $\Delta$ A-A-D-C, $\Delta$ A-A-D-A, $\Delta$ CA-D-A, and $\triangle \mathrm{C}-\mathrm{C}-\mathrm{C}-\mathrm{C}$. A set of energy parameters characteristic of sulfate groups was added to the force field, making it suitable for the molecular modeling of sulfated carbohydrates (26). The three terminal oxygen atoms in sulfate groups were generated as equivalent, so $\mathrm{C}_{x}-\mathrm{O}_{x}-\mathrm{S}-$ $\mathrm{O}_{\mathrm{S}}$ was left as corresponding to any staggered conformation. For the $\mu_{4}$ angle in GalNAc4S (Figure 2c), only the most favorable conformation at $243^{\circ}$ was considered (27), whereas for GalNAc6S only the trans orientation of the $\mu_{6}$ angle was considered, as it is the most favorable conformation (Figure 2d) $(26,28)$. In all calculations, the $N$-acetyl groups were positioned in their preferred trans orientation with $\mathrm{C}_{1}-\mathrm{C}_{2}-$ $\mathrm{N}_{2}-\mathrm{C}_{\mathrm{O}}=100-140^{\circ}$ and a trans orientation of the CO-
$\mathrm{NH}$ bond $(29,30)$. The oxygen atoms of the carboxyl group were generated as equivalent, and the corresponding exocyclic torsion angle was not explored.

For each disaccharide, 12 starting geometries were generated, taking into account the hydroxymethyl group orientations gauche-gauche (gg), gauche-trans ( $g$ t), and transgauche ( $\operatorname{tg}$ ) ( $\omega$ close to $-60^{\circ}, 60^{\circ}$, and $180^{\circ}$, respectively) in the GalNAc residue and the secondary hydroxyl groups [clockwise (c) and counterclockwise (r) orientations] in both monomers. The 12 starting points were constructed with the carbohydrate molecular builder POLYS (31) and fully minimized in energy. The relaxed maps were computed using rigid rotation in $10^{\circ}$ intervals for $\varphi$ and $\psi$ spanning the whole angular range, followed by minimization using the block diagonal method with a termination criterion of $n \times 0.00003$ $\mathrm{kcal} / \mathrm{mol}(n=$ number of atoms). The adiabatic map was finally constructed for each disaccharide by using the lowest energy conformation from the relaxed maps for each grid point. In the calculations, a dielectric constant of 80 was used, which is appropriate to represent an aqueous environment. The isoenergy contour maps were drawn using the program Xfarbe (32).

(C) Building of Oligosaccharides. The oligosaccharides were built using the graphics program Sybyl (Tripos Associates, St. Louis, MO). Solvent-accessible surfaces were calculated with the Molcad program (33), and electrostatic potentials were calculated using atomic charges corresponding to parameters developed for carbohydrates (34).

\section{RESULTS AND DISCUSSION}

${ }^{1} H$ NMR Spectroscopy of $\triangle C$ - $A-D-C$. Table 1 presents the assignments of most of the ${ }^{1} \mathrm{H}$ chemical shifts of the octasaccharide $\Delta^{4,5} \mathrm{HexA}(\alpha 1-3) \mathrm{GalNAc} 6 S(\beta 1-4) \mathrm{GlcA}(\beta 1-$ 3) GalNAc $4 S(\beta 1-4)$ GlcA2 $S(\beta 1-3)$ GalNAc6 $S(\beta 1-4)$ GlcA$(\beta 1-3)$ GalNAc6S $(\Delta \mathrm{C}$-A-D-C), deduced from 2D-TOCSY measurements (mixing times 10, 50, and $100 \mathrm{~ms}$ ) at temperatures ranging from 277 to $333 \mathrm{~K}$. As a typical example, in Figure $3 a$ the relevant part of a TOCSY spectrum recorded at $277 \mathrm{~K}$ with a mixing time of $100 \mathrm{~ms}$ is depicted. The chemical shifts were found to be fairly constant within this temperature range, the largest chemical shift difference not exceeding $\Delta \delta=0.05 \mathrm{ppm}$ between spectra recorded at 277 and $299 \mathrm{~K}$ (see compound Vb, $\Delta \mathrm{C}-\mathrm{A}-\mathrm{D}-\mathrm{C}$, in ref 13 ). For instance, GalNAc-1 $\alpha$ H-1 shifts between $\delta 5.16$ (277 K) and 5.21 ( $299 \mathrm{~K})$. In Figure $3 \mathrm{~b}$ the relevant part of the $900 \mathrm{MHz}$ 2D-NOESY spectrum (mixing time $100 \mathrm{~ms}$ ) of $\Delta \mathrm{C}$-A-D-C, recorded at $277 \mathrm{~K}$, is presented. At the chosen temperature the $\mathrm{H}^{2} \mathrm{HO}$ signal is not overlapping with any of the signals of the octasaccharide. Although the $\mathrm{H}-1$ signals of GlcA-2, GalNAc-3, GalNAc-5, and GalNAc-7 are overlapping at $\delta 4.54$, the NOESY spectrum could be assigned without any ambiguity, showing the interresidual cross-peaks expected. At short mixing times (such as $100 \mathrm{~ms}$ ), where the NOE build up curves are relatively linear, interproton distances can be directly deduced from NOE intensities (20). In Table 2 the ${ }^{1} \mathrm{H}-{ }^{-1} \mathrm{H}$ interresidue distances, deduced from NOE volumes using the isolated spin pair approximation, are shown.

Molecular Modeling of the Octasaccharides $\triangle C-A-D-C$, $\triangle A-A-D-C, \triangle A-A-D-A, \triangle C-A-D-A$, and $\triangle C-C-C-C$. (A) Conformational Properties of the Constituent Disaccharides. 


\begin{tabular}{|c|c|c|c|c|c|}
\hline residue & $\begin{array}{c}\text { reporter } \\
\text { group }\end{array}$ & $\begin{array}{c}\delta(\mathrm{ppm}) \\
\text { at } \\
277 \mathrm{~K}\end{array}$ & residue & $\begin{array}{c}\text { reporter } \\
\text { group }\end{array}$ & $\begin{array}{c}\delta(\mathrm{ppm} \\
\text { at } \\
277 \mathrm{~K}\end{array}$ \\
\hline \multirow[t]{8}{*}{ GalNAc-1 } & $\mathrm{H}-1 \alpha, \mathrm{H}-1 \beta$ & $5.16,4.68$ & \multirow{8}{*}{ GalNAc-5 } & $\mathrm{H}-1$ & 4.54 \\
\hline & $\mathrm{H}-2$ & 4.27 & & $\mathrm{H}-2$ & 4.01 \\
\hline & $\mathrm{H}-3$ & 4.01 & & $\mathrm{H}-3$ & 4.07 \\
\hline & $\mathrm{H}-4$ & $4.19^{b}$ & & $\mathrm{H}-4$ & $4.74^{c}$ \\
\hline & H-5 & $4.34^{b}$ & & H-5 & nd \\
\hline & H-6 & $4.19^{b}$ & & H-6 & nd \\
\hline & $\mathrm{H}-6^{\prime}$ & $4.14^{b}$ & & H- $6^{\prime}$ & nd \\
\hline & NAc & 2.02 & & NAc & 2.03 \\
\hline \multirow{5}{*}{ GlcA-2 } & $\mathrm{H}-1^{\alpha}, \mathrm{H}-1^{\beta}$ & $4.54,4.48$ & \multirow{5}{*}{ GlcA-6 } & $\mathrm{H}-1$ & 4.43 \\
\hline & $\mathrm{H}-2$ & 3.34 & & $\mathrm{H}-2$ & 3.34 \\
\hline & $\mathrm{H}-3^{\alpha}, \mathrm{H}-3^{\beta}$ & $3.58,3.56$ & & $\mathrm{H}-3$ & 3.55 \\
\hline & $\mathrm{H}-4^{\alpha}, \mathrm{H}-4^{\beta}$ & $3.69,3.64$ & & $\mathrm{H}-4$ & 3.71 \\
\hline & H-5 & nd & & H-5 & $3.68^{b}$ \\
\hline \multirow[t]{8}{*}{ GalNAc-3 } & $\mathrm{H}-1$ & 4.54 & \multirow[t]{8}{*}{ GalNAc-7 } & $\mathrm{H}-1$ & 4.54 \\
\hline & $\mathrm{H}-2$ & 3.92 & & $\mathrm{H}-2$ & 4.01 \\
\hline & $\mathrm{H}-3$ & 4.01 & & $\mathrm{H}-3$ & 3.92 \\
\hline & $\mathrm{H}-4$ & $4.18^{b}$ & & $\mathrm{H}-4$ & $4.18^{b}$ \\
\hline & H-5 & nd & & H-5 & nd \\
\hline & H-6 & $4.22^{b}$ & & H-6 & $4.22^{b}$ \\
\hline & H-6 $6^{\prime}$ & nd & & H- $6^{\prime}$ & nd \\
\hline & NAc & 2.03 & & NAc & 2.06 \\
\hline \multirow[t]{5}{*}{ GlcA-4 } & $\mathrm{H}-1$ & 4.71 & \multirow[t]{5}{*}{$\Delta^{4,5}$ HexA-8 } & $\mathrm{H}-1$ & 5.17 \\
\hline & $\mathrm{H}-2$ & 4.11 & & $\mathrm{H}-2$ & 3.76 \\
\hline & $\mathrm{H}-3$ & 3.80 & & $\mathrm{H}-3$ & 4.08 \\
\hline & $\mathrm{H}-4$ & 3.81 & & $\mathrm{H}-4$ & 5.87 \\
\hline & $\mathrm{H}-5$ & $4.01^{c}$ & & & \\
\hline
\end{tabular}

${ }^{a}$ Chemical shifts are given relative to internal acetone $(\delta 2.225)$ in ${ }^{2} \mathrm{H}_{2} \mathrm{O}$ mostly at $277 \mathrm{~K}$ and sometimes at 299 or $333 \mathrm{~K}$ (see footnotes $b$ and $c$ ) and at $\mathrm{p}^{2} \mathrm{H} 7$ (19). nd $=$ not determined. ${ }^{b}$ Values determined at $299 \mathrm{~K} .{ }^{c}$ Values determined at $333 \mathrm{~K}$.

For the construction of models of the five octasaccharides $\Delta$ C-A-D-C, $\Delta$ A-A-D-C, $\Delta$ A-A-D-A, $\Delta$ C-A-D-A, and $\Delta \mathrm{C}-$ $\mathrm{C}-\mathrm{C}-\mathrm{C}$, eight different disaccharide elements have to be taken into account: $\operatorname{GlcA}(\beta 1-3) \operatorname{GalNAc} 4 S(\mathrm{~A}), \Delta^{4,5} \mathrm{HexA}(\alpha 1-$ 3)GalNAc4S ( $\triangle \mathrm{A})$, GlcA $(\beta 1-3)$ GalNAc6S $(\mathrm{C}), \Delta^{4,5} \mathrm{HexA}$ $(\alpha 1-3)$ GalNAc6s $(\Delta \mathrm{C}), \operatorname{GlcA} 2 S(\beta 1-3)$ GalNAc6s (D), GalNAc4S $(\beta 1-4)$ GlcA (bridge $\Delta \mathrm{A} \rightarrow \mathrm{A})$, GalNAc6 $S(\beta 1-$ 4)GlcA (bridge $\Delta \mathrm{C} \rightarrow \mathrm{A}, \Delta \mathrm{C} \rightarrow \mathrm{C}, \mathrm{C} \rightarrow \mathrm{C}, \mathrm{D} \rightarrow \mathrm{A}, \mathrm{D} \rightarrow$ $\mathrm{C}$ ), and GalNAc4S( $\beta 1-4)$ GlcA $2 S$ (bridge $\mathrm{A} \rightarrow \mathrm{D}$ ). These disaccharides were studied by a systematic grid search using the MM3 program. Previously, the adiabatic $(\varphi, \psi)$ maps of GlcA-GalNAc4S (A), GlcA-GalNAc6S (C), GalNAc4SGlcA, and GalNAc6S-GlcA have been calculated and are presented in Table 3 (27). Figure 4 shows the adiabatic maps of the four remaining disaccharides GlcA2S-GalNAc6S (D), GalNAc4S-GlcA2 $S, \Delta^{4,5} \mathrm{HexA-GalNAc6S}(\Delta \mathrm{C})$, and $\Delta^{4,5}$ HexA-GalNAc4S $(\Delta \mathrm{A})$, computed with a dielectric constant of 80 , and the minima are listed in Table 3 . The $(\varphi, \psi)$ values of the global minima present in the four adiabatic maps are close to the ones derived from molecular dynamics simulations of chondroitin sulfate, using explicitly water $\left[\left(290^{\circ}\right.\right.$, $\left.90^{\circ}\right)$ for the $(\beta 1-3)$ linkage and $\left(290^{\circ}, 240^{\circ}\right)$ for the $(\beta 1-$ 4) linkage] (30).

The various maps share global patterns typical of $(1 \rightarrow 3)$ diequatorial and $(1 \rightarrow 4)$ diequatorial linked ${ }^{4} C_{1}$ hexopyranose residues, respectively, quite comparable to those found in the studies on hyaluronan (29) and chondroitin sulfate (27).

As is evident from Figure 4A,C, for GlcA2S-GalNAc6S (D) and $\Delta^{4,5} \mathrm{HexA}$-GalNAc6S $(\Delta \mathrm{C})$ the main low-energy region contains the a and $\mathrm{b}$ wells, the $(\varphi, \psi)$ values being the same for both dimers: $\left(270^{\circ}, 70^{\circ}\right)$ for $\mathrm{a}$, and $\left(80^{\circ}, 220^{\circ}\right)$ for $\mathrm{b}$. These two minima are very close in energy $(\Delta E<$ $0.5 \mathrm{kcal} / \mathrm{mol})$ and separated by low-energy barriers $(<0.5$ $\mathrm{kcal} / \mathrm{mol}$ ). The minima appear to be similar to the ones previously determined for GlcA-GalNAc6S (C) (see Figure $2 \mathrm{f}$ in ref 27). These findings suggest that the sulfate group at position 2 or the double bond between $C 4$ and $C 5$ in $\Delta^{4,5}$ HexA has only limited influence on the global shapes of the energy maps. The low-energy zone below $8 \mathrm{kcal} / \mathrm{mol}$ is wider for $\Delta^{4,5} \mathrm{HexA}$-GalNAc6 $S$ than for GlcA2S-GalNAc6 $S$, which is interpreted as a reduced flexibility attributed to the 2-Osulfate group next to the glycosidic linkage in GlcA2SGalNAc6S. The adiabatic maps of both disaccharides also present other wells of higher energy: $3.8 \mathrm{kcal} / \mathrm{mol}$ above the global minimum at about $\left(270^{\circ}, 280^{\circ}\right)$ for both disaccharides and at $\left(60^{\circ}, 110^{\circ}\right)$ for $\Delta^{4,5} \mathrm{HexA}-G a l N A c 6 S$.

The global shape of the adiabatic map of GalNAc $4 S$ GlcA2S (Figure 4B) is comparable to that of GalNAc4SGlcA (see Figure $2 \mathrm{~d}$ in ref 27 ). The map presents a global minimum at $\left(280^{\circ}, 230^{\circ}\right)$ and local minima of higher energy, $1.5-4.9 \mathrm{kcal} / \mathrm{mol}$ above the global minimum, at $\left(270^{\circ}, 50^{\circ}\right)$ and $\left(60^{\circ}, 240^{\circ}\right)$. Because the main domain of the adiabatic map of GalNAc $4 S$-GlcA $2 S$ presents only one minimum, in contrast to the map of GalNAc4S-GlcA (27), it seems that the glycosidic linkage in the first case is more rigid than in the second case.

The adiabatic map of $\Delta^{4,5} \mathrm{HexA}-$ GalNAc4S (Figure 4D) has a global shape similar to that of GlcA-GalNAc4S (see Figure $2 c$ in ref 27), but it is less extended. It exhibits an a well at $\left(280^{\circ}, 100^{\circ}\right)$ in the low-energy region. Two other domains of higher energy, $2.4-3.8 \mathrm{kcal} / \mathrm{mol}$ above the global minimum, are also present, and these $\mathrm{b}$ and $\mathrm{c}$ wells are located at $\left(60^{\circ}, 110^{\circ}\right)$ and $\left(210^{\circ}, 90^{\circ}\right)$, respectively. Local minimum $\mathrm{c}$ was not found on the adiabatic map of GlcAGalNAc4S, which is probably due to the presence of the double bond between $\mathrm{C} 4$ and $\mathrm{C} 5$ in $\Delta^{4,5} \mathrm{HexA}$.

For all minima, the hydroxymethyl group of the GalNAc residues occurs in the $g t$ orientation, usually the most represented rotamer in solution for galactoses (35). As reported previously (28), the sulfate groups in GlcA2S and in GalNAc6S are in an eclipsed orientation with respect to $\mathrm{H}-1$ and H-5, respectively (GlcA2 $S, \mu_{2}=120^{\circ}$; GalNAc6S, $\mu_{6}=180^{\circ}$ ) (Figure 2b,d). In GalNAc4S, the sulfate group presents an anti orientation $\left(\mu_{4}=245^{\circ}\right)$ with regard to $\mathrm{H}-3$, in accordance with previous findings $(26-28)$ (Figure $2 \mathrm{c}$ ). Low steric interactions between atoms cause the preference for eclipsed and anti orientations.

(B) Construction of the Octasaccharides. By using the graphics program Sybyl, the octasaccharide $\triangle \mathrm{C}-\mathrm{A}-\mathrm{D}-\mathrm{C}(\mathbf{8}-$ 7-6-5-4-3-2-1) was built from the constituting disaccharides, modeled above. For each disaccharide, combinations of the energy minima $\mathrm{a}$ and $\mathrm{b}$ were used, except for 5-4. Here, only minimum a was considered, because the other minima were at least $1.9 \mathrm{kcal} / \mathrm{mol}$ higher in energy, separated by high-energy barriers $(>7 \mathrm{kcal} / \mathrm{mol})$, and were not located in the main domain. For the disaccharides 8-7, $\mathbf{7}-\mathbf{6}, \mathbf{6}-\mathbf{5}, \mathbf{4}-\mathbf{3}, \mathbf{3}-\mathbf{2}$, and $\mathbf{2}-\mathbf{1}$, the distances between the interglycosidic protons calculated for both minima $\mathrm{a}$ and $\mathrm{b}$ were in agreement with the NOE data. For the disaccharide $\mathbf{5 - 4}$, the interresidual distance $\mathbf{5}_{\mathbf{1}}, \mathbf{4}_{\mathbf{4}}$ calculated for minimum a was in agreement with the distance measured in the NOE spectrum. Therefore, while fitting with the NMR data, $2^{6}=$ 64 conformations could be generated for $\triangle \mathrm{C}-\mathrm{A}-\mathrm{D}-\mathrm{C}$. 

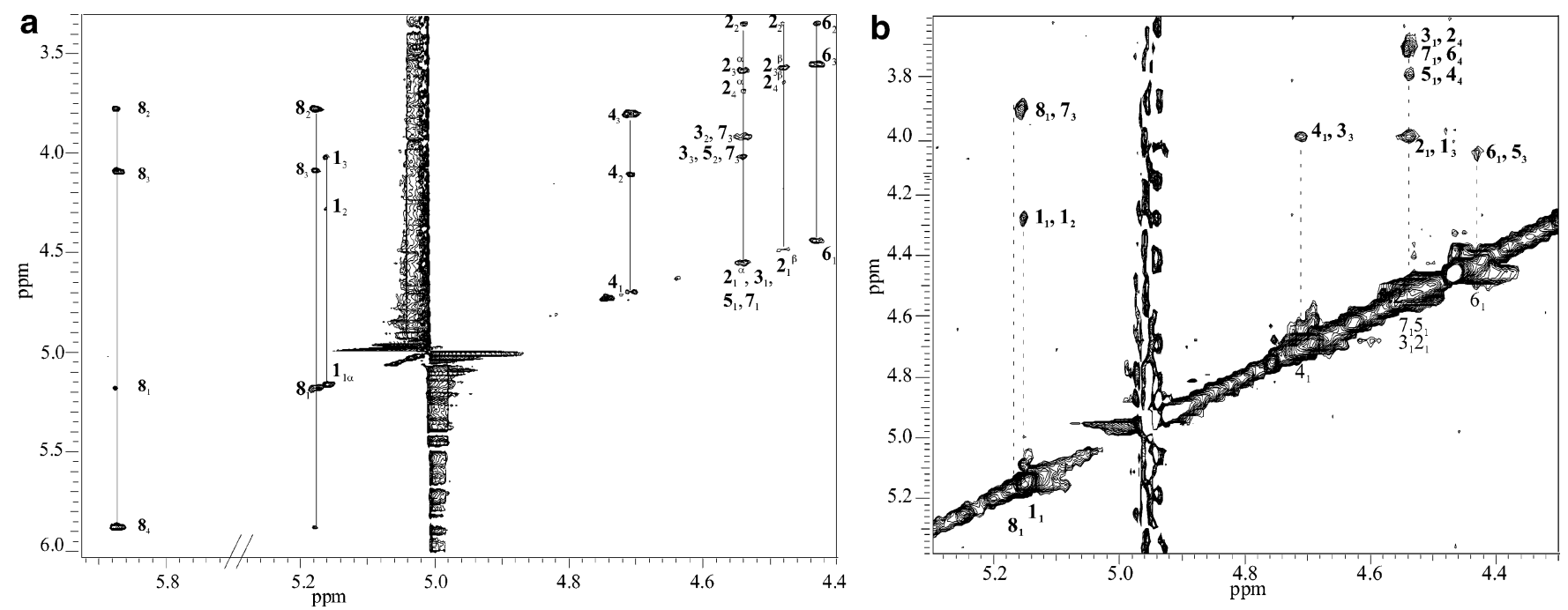

FIGURE 3: (a) $900 \mathrm{MHz}$ TOCSY spectrum (mixing time, $100 \mathrm{~ms}$ ) of $\triangle \mathrm{C}-\mathrm{A}-\mathrm{D}-\mathrm{C}$ recorded at $277 \mathrm{~K}$. (b) $900 \mathrm{MHz} \mathrm{NOESY}$ spectrum (mixing time, $100 \mathrm{~ms}$ ) of $\Delta \mathrm{C}$-A-D-C recorded at $277 \mathrm{~K}$. The code $\mathbf{2}_{1}$ denotes the chemical shift of $\mathrm{H}-1$ of residue 2 , etc.; in the NOESY spectrum, $\mathbf{2}_{1}, \mathbf{1}_{3}$ stands for an interresidual connectivity between residues $\mathbf{2} \mathrm{H}-1$ and $\mathbf{1} \mathrm{H}-3$, etc. Cross-peaks between protons belonging to the same scalar coupling network are indicated near a dotted line. The asterisk indicates a contamination.

Table 2: Interresidual Distances Observed in the NOESY Spectrum and Calculated in the Model for $\Delta \mathrm{C}-\mathrm{A}-\mathrm{D}-\mathrm{C}^{a}$

\begin{tabular}{ccll}
\hline & & \multicolumn{2}{c}{ distances $(\AA)$} \\
\cline { 3 - 4 } proton pair & chemical shift $(\mathrm{ppm})$ & obsd & calcd \\
\hline $\mathbf{2}_{1}, \mathbf{1}_{3}$ & $4.54 \rightarrow 4.01$ & 2.2 & 2.2 \\
$\mathbf{3}_{1}, \mathbf{2}_{4}$ & $4.54 \rightarrow 3.69$ & $(2.5)$ & 2.4 \\
$\mathbf{4}_{1}, \mathbf{3}_{3}$ & $4.71 \rightarrow 4.01$ & 2.3 & 2.2 \\
$\mathbf{5}_{1}, \mathbf{4}_{4}$ & $4.54 \rightarrow 3.81$ & 2.3 & 2.2 \\
$\mathbf{6}_{1}, \mathbf{5}_{3}$ & $4.43 \rightarrow 4.07$ & 2.3 & 2.3 \\
$\mathbf{7}_{1}, \mathbf{6}_{4}$ & $4.54 \rightarrow 3.71$ & $(2.4)$ & 2.4 \\
$\mathbf{8}_{1}, \mathbf{7}_{3}$ & $5.17 \rightarrow 3.92$ & 2.2 & 2.2 \\
\hline
\end{tabular}

${ }^{a}$ Distances derived from overlapping peaks are indicated in parentheses. Observed distances are given relative to GalNAc- $1 \alpha \mathrm{H}-1 / \mathrm{H}-2$ $(2.5 \AA) .2_{1}, \mathbf{1}_{3}$ stands for an interresidual connectivity between residues GlcA-2 H-1 and GalNAc-1 H-3 etc.

Superimposition of all possible conformations (Figure 5a) demonstrated that the oligosaccharide has certain flexibility but, nevertheless, has a tendency to adopt an extended conformation with variations at both ends. Close inspection of the structure shows that the negative charges are clustered in restricted areas. In this particular case, and because of the extended shapes of the individual conformers, it was possible to design an "average" conformation by fixing all flexible glycosidic linkages in a conformation in between the $\mathrm{a}$ and $\mathrm{b}$ values of $(\varphi, \psi)$. The resulting conformer (Figure $5 b)$ has the advantage of displaying negative charges that are in positions corresponding to the center of the clusters observed when taking flexibility into account.

In order to compare the charge repartition within the five octasaccharides $\Delta \mathrm{C}$-A-D-C, $\Delta \mathrm{A}$-A-D-C, $\Delta \mathrm{A}$-A-D-A, $\Delta \mathrm{C}$ $\mathrm{A}-\mathrm{D}-\mathrm{A}$, and $\triangle \mathrm{C}-\mathrm{C}-\mathrm{C}-\mathrm{C}$, for each of them an average conformation was built, following the protocol described above. Table 4 presents the average dihedral angles used to construct these conformations. Interproton distances of interest, calculated from the average conformation of $\Delta \mathrm{C}$ A-D-C, are presented in Table 2 along with distances "observed" in the NOESY spectrum. These observed distances matched the distances in the model. It has to be noted that the shortest distance observed in the NOESY experiments was $2.5 \AA$ A Reciprocally, no additional short distances in the model smaller than $2.6 \AA$ were observed in the NOESY spectrum.

Figure 6 shows the average conformations of the five octasaccharides including their negative charges, as well as their accessible surfaces color-coded accordingly to the electric potential (blue $\rightarrow$ red: negative $\rightarrow$ positive). It is clear that all of the molecules adopt the same extended shape, but significant differences are observed when looking at the repartition of the negative charges. Four of the five octasaccharides contain a disaccharide unit $\mathrm{D}$ with two sulfate groups. In the exception, $\Delta \mathrm{C}-\mathrm{C}-\mathrm{C}-\mathrm{C}$, the concentration of negative charges at the surface of the molecule is smaller in the center, when compared with the other octasaccharides. The terminal unsaturated uronic acids give a flattened shape to disaccharides $\Delta \mathrm{A}$ and $\Delta \mathrm{C}$ compared to disaccharides $\mathrm{A}$ $[\mathrm{GlcA}(\beta 1-3) \mathrm{GalNAc} 4 S]$ and $\mathrm{C}[\mathrm{GlcA}(\beta 1-3)$ GalNAc6S]. In disaccharides $\mathrm{A}$ and $\Delta \mathrm{A}$, the carboxylic group of GlcA $/ \Delta^{4,5}$ HexA and the sulfate group of GalNAc $4 S$ are relatively close in space, so that the negative charges are concentrated in the same area. In contrast, in disaccharides $\mathrm{C}$ and $\Delta \mathrm{C}$, GalNAc bears a sulfate group at the 6 position, yielding exocyclic negative tails and, thus, a spreading of negative charge concentration.

Correlation between Structural Studies and Immunological Data. At present, no structural information is available on the complexes between CS and recognizing antibodies. However, using a combination of specific recognition data and the models calculated here can give some hints about the basis for the antibody binding.

The primary structural difference between $\triangle \mathrm{C}-\mathrm{C}-\mathrm{C}-\mathrm{C}$, which is not recognized by any of the three antibodies (CS56, MO-225, and 473HD), and the other octasaccharides, $\Delta \mathrm{C}-\mathrm{A}-\mathrm{D}-\mathrm{C}, \Delta \mathrm{A}-\mathrm{A}-\mathrm{D}-\mathrm{C}, \Delta \mathrm{A}-\mathrm{A}-\mathrm{D}-\mathrm{A}$, and $\Delta \mathrm{C}-\mathrm{A}-\mathrm{D}-\mathrm{A}$, is the absence or presence of one extra sulfate group in the middle of the molecule. Responsible for this difference is the disaccharide D [GlcA2S( $\beta 1-3)$ GalNAc6S] element, having a 2-O-sulfated GlcA unit. It seems that the extra sulfate group plays a main role in the antibody recognition.

Recent ELISA data (17) established that mAb CS-56 binds to the four octasaccharides following the preference order 
Table 3: Low-Energy Conformers of the Eight Disaccharides

\begin{tabular}{|c|c|c|c|c|c|c|c|}
\hline disaccharide $^{a}$ & minimum & $\varphi$ & $\psi$ & $\omega$ & $\mu_{\mathrm{GalNAc}}$ & $\mu_{\mathrm{GlcA}}$ & $\Delta E^{b}$ \\
\hline \multirow[t]{4}{*}{$1, \beta$-D-Glc $p$ A- $(1 \rightarrow 3)-\beta$-D-Gal $p$ NAc $4 S$} & $\mathrm{a}$ & 280 & 90 & gt & 243 & & 0.0 \\
\hline & $\mathrm{b}$ & 280 & 130 & $g t$ & 247 & & 0.7 \\
\hline & $\mathrm{c}$ & 60 & 110 & $g t$ & 246 & & 3.6 \\
\hline & $\mathrm{d}$ & 270 & 280 & $g t$ & 229 & & 4.8 \\
\hline \multirow{5}{*}{$2, \beta$-D-Gal $p N A c 4 S$ - $(1 \rightarrow 4)-\beta$-D-Glc $p \mathrm{~A}$} & $\mathrm{a}$ & 260 & 210 & $g t$ & 243 & & 0.4 \\
\hline & $\mathrm{b}$ & 280 & 250 & $g t$ & 243 & & 0.0 \\
\hline & $\mathrm{c}$ & 270 & 60 & $g t$ & 243 & & 3.0 \\
\hline & d & 60 & 240 & $g t$ & 243 & & 4.4 \\
\hline & $\mathrm{e}$ & 80 & 270 & $g t$ & 243 & & 4.5 \\
\hline \multirow{4}{*}{$3, \beta$-D-Glc $p$ A- $(1 \rightarrow 3)-\beta$-D-Gal $p$ NAc $6 S$} & a & 270 & 70 & $g t$ & 196 & & 0.0 \\
\hline & $\mathrm{b}$ & 280 & 140 & $g t$ & 199 & & 0.7 \\
\hline & c & 60 & 110 & $g t$ & 197 & & 3.6 \\
\hline & $\mathrm{d}$ & 260 & 280 & $g t$ & 197 & & 4.8 \\
\hline \multirow[t]{5}{*}{$4, \beta$-D-Gal $p$ NAc $6 S-(1 \rightarrow 4)-\beta$-D-Glc $p$ A } & a & 260 & 190 & $g t$ & 218 & & 0.4 \\
\hline & $\mathrm{b}$ & 280 & 250 & gt & 211 & & 0.0 \\
\hline & $\mathrm{c}$ & 280 & 70 & $g t$ & 190 & & 3.0 \\
\hline & $\mathrm{d}$ & 60 & 240 & $g t$ & 186 & & 4.6 \\
\hline & $\mathrm{e}$ & 80 & 270 & $g t$ & 188 & & 4.9 \\
\hline \multirow{3}{*}{$5, \beta$-D-Glc $p$ A2 $S$-( $1 \rightarrow 3)-\beta$-D-Gal $p$ NAc $6 S$} & a & 270 & 70 & $g t$ & 182 & 118 & 0.0 \\
\hline & $\mathrm{b}$ & 280 & 140 & gt & 182 & 126 & 0.0 \\
\hline & c & 260 & 280 & gt & 181 & 124 & 3.8 \\
\hline \multirow[t]{3}{*}{$6, \beta$-D-Gal $p$ NAc $4 S$ - $(1 \rightarrow 4)-\beta$-D-GlcpA2 $S$} & a & 280 & 230 & $g t$ & 243 & 120 & 0.0 \\
\hline & $\mathrm{b}$ & 270 & 50 & $g t$ & 243 & 120 & 1.9 \\
\hline & $\mathrm{c}$ & 60 & 240 & $g t$ & 243 & 119 & 4.5 \\
\hline \multirow[t]{4}{*}{$7, \alpha-\Delta^{4,5}$ HexA-( $(1 \rightarrow 3)-\beta$-D-Gal $p$ NAc6 $S$} & a & 270 & 70 & $g t$ & 181 & & 0.0 \\
\hline & $\mathrm{b}$ & 280 & 140 & gt & 181 & & 0.5 \\
\hline & $\mathrm{c}$ & 270 & 280 & $g t$ & 181 & & 3.8 \\
\hline & $\mathrm{d}$ & 60 & 110 & $g t$ & 182 & & 3.8 \\
\hline \multirow[t]{3}{*}{$8, \alpha-\Delta^{4,5} \mathrm{HexA}-(1 \rightarrow 3)-\beta$-D-Gal $p$ NAc $4 S$} & $\mathrm{a}$ & 280 & 100 & gt & 244 & & 0.0 \\
\hline & $\mathrm{b}$ & 60 & 110 & $g t$ & 247 & & 3.9 \\
\hline & $\mathrm{c}$ & 210 & 90 & $g t$ & 239 & & 2.4 \\
\hline
\end{tabular}

${ }^{a} 1-4$ taken from ref 27 and $5-8$ calculated in the present study. ${ }^{b}$ Relative energy $(\mathrm{kcal} / \mathrm{mol})$.
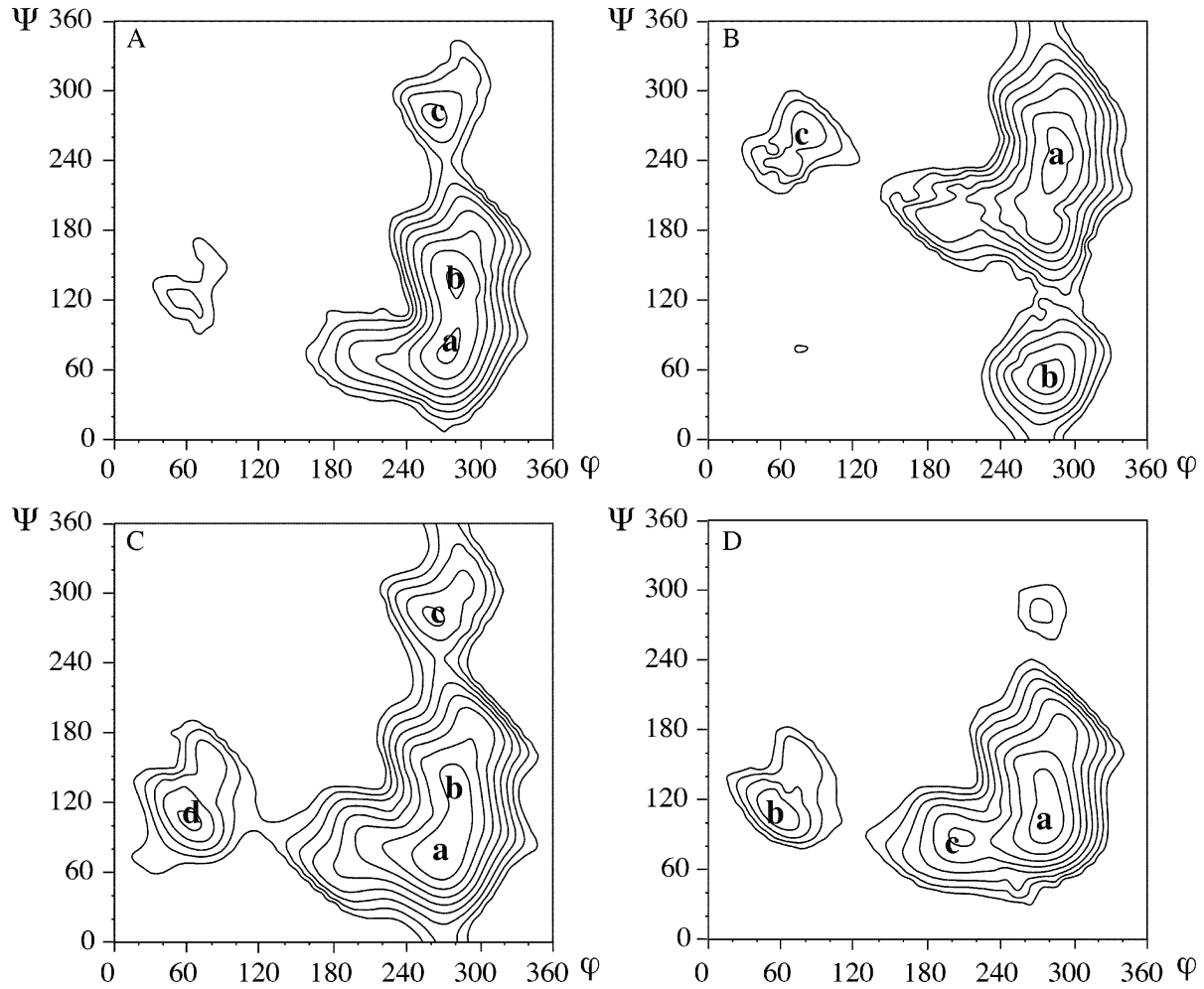

Figure 4: Adiabatic maps of (A) $\beta$-D-Glc $p$ A2 $S$ - $(1 \rightarrow 3)-\beta$-D-Gal $p$ NAc6 $S$, (B) $\beta$-D-Gal $p N A c 4 S$ - $(1 \rightarrow 4)-\beta$-D-Glc $p$ A $2 S,(C) \alpha-\Delta^{4,5} \mathrm{HexA}-(1 \rightarrow 3)-$ $\beta$-D-GalpNAc6S, and (D) $\alpha-\Delta^{4,5} \mathrm{HexA}-(1 \rightarrow 3)-\beta$-D-Gal $p N A c 4 S$. Isocontour levels are drawn at $1 \mathrm{kcal} / \mathrm{mol}$ increments up to $8 \mathrm{kcal} / \mathrm{mol}$ above the global energy minimum. Codes a, b, c, and d represent the energy minima, a being the global energy minimum and b, c, and $d$ local minima (see Table 4).

$\Delta \mathrm{C}$-A-D-C $>\Delta \mathrm{A}-\mathrm{A}-\mathrm{D}-\mathrm{C}>\Delta \mathrm{A}-\mathrm{A}-\mathrm{D}-\mathrm{A}>\Delta \mathrm{C}-\mathrm{A}-\mathrm{D}-\mathrm{A}$. The preference of hexasaccharide A-D-C over A-D-A has to be caused by the more exposed, relatively flexible exocyclic, negatively charged tail in the "reducing site" GalNAc6S residue of element $\mathrm{C}$ (Figure 6a,c versus Figure 6b,d). The binding sequence $\underline{\Delta \mathrm{C}-\mathrm{A}-\mathrm{D}-\mathrm{C}}>\underline{\Delta \mathrm{C}-\mathrm{A}-\mathrm{D}-\mathrm{A}}>\underline{\Delta \mathrm{A}-\mathrm{A}-\mathrm{D}-\mathrm{C}}$ 


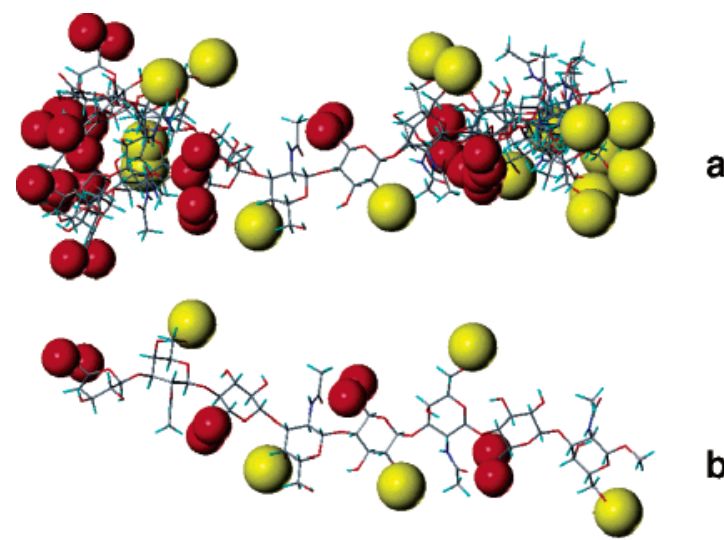

FIGURE 5: (a) Graphical representation of the lowest energy conformation family of the octasaccharide $\Delta$ C-A-D-C. Sixty-four low-energy conformations are represented together. (b) Average conformation of $\Delta \mathrm{C}$-A-D-C, drawn with the $(\varphi, \psi)$ values presented in Table 4. Red balls represent the oxygen atoms of the carboxylic acid groups and yellow balls the sulfate atoms.

$>\Delta$ A-A-D-A, established for mAb MO-225 (17), indicates a preference for $\Delta \mathrm{C}$ in the terminal hexasaccharides $(\Delta \mathrm{C}$ A-D versus $\Delta A-A-D$ ) (Figure 6a,b versus Figure 6c,d), with a fine-tuning in the preference for a reducing site GalNAc6S (Figure 6a versus Figure 6b). Here, the importance of the more exposed, relatively flexible exocyclic, negatively charged tails in both the nonreducing $\Delta \mathrm{C}$ and the reducing $\mathrm{C}$ element for the antibody recognition is clearly indicated. MAb 473HD recognizes structures containing at least one A-D or D-A tetrasaccharide unit (17). As indicated already, this antibody recognizes a unique CS epitope in DSD-1-PG (phosphacan), which is an ectodomain of the signal transducing receptor-like protein tyrosine phosphatase PTP $\xi /$ $\operatorname{RPTP} \beta(11)$. The epitope appears to contain L-iduronic acid (IdoA) as well, since it is eliminated by chondroitinase ABC but not by chondroitinase ACII (11). Such CS/DS (dermatan sulfate) hybrid sequences containing iA [ $\operatorname{IdoA}(\alpha 1-3)$ GalNAc4S], iB [IdoA2S( $\alpha 1-3)$ GalNAc4S], iD [IdoA $(\alpha 1-$ 3)GalNAc6S], and/or $\mathrm{iE}[\operatorname{IdoA}(\alpha 1-3)$ GalNAc4S,6S] disaccharides exhibit neurite outgrowth promoting activity toward embryonic mouse hippocampal neurons through binding to pleiotrophin, the target sugar sequences of which overlap the epitope sugar sequences of $473 \mathrm{HD}$, as recently illustrated in ref 36. More recently, octasaccharide sequences, recognized by a heparin-binding growth factor pleiotrophin, were isolated from the CS/DS hybrid chains of embryonic pig brains. They were derived from the corresponding nonasaccharide sequences, which contained A-D, iA-D, C-D, or iC-D tetrasaccharide, and were flanked by two IdoA residues (37). In view of the data obtained from the present study, the above-described evidence may suggest a contribution of the IdoA residue(s) in the vicinity of the A-D sequence to the
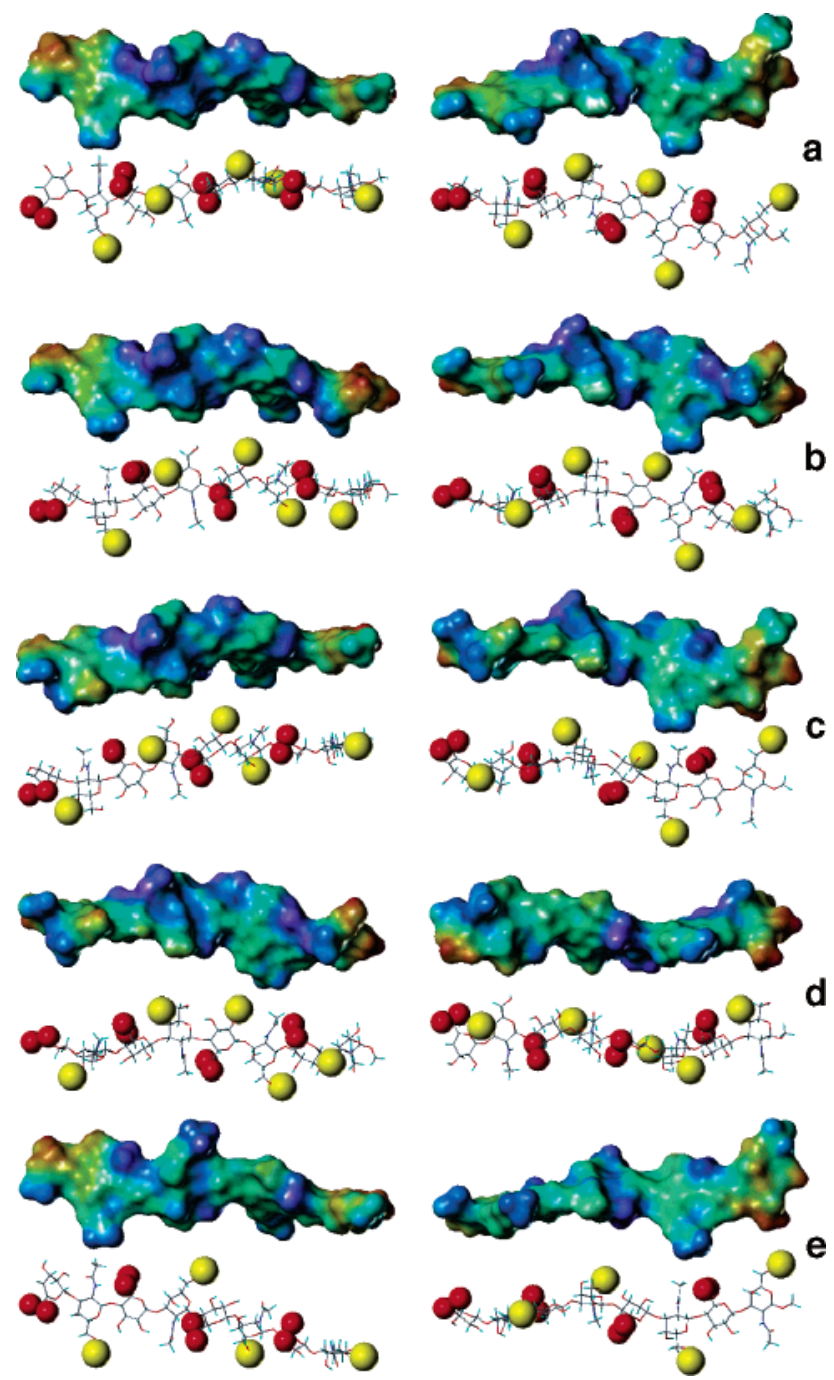

FIGURE 6: Average conformations of (a) $\Delta \mathrm{C}$-A-D-C, (b) $\Delta \mathrm{C}$-AD-A, (c) $\Delta$ A-A-D-C, (d) $\Delta$ A-A-D-A, and (e) $\Delta$ C-C-C-C, drawn with the $(\varphi, \psi)$ values presented in Table 4 . The electrostatic potential is represented with blue $(-)$ and red $(+)$ scale surfaces. Red balls represent the oxygen atoms of the carboxylic acid groups and yellow balls the sulfate atoms.

concentration of the negative charges in the center of the 473HD epitope sequences, providing additional specificity.

Summarizing, the structural studies presented in this study demonstrate clearly that the octasaccharides, binding preferentially to mAbs CS-56 and MO-225, present some structural differences, wherein the exocyclic negatively charged tails play an important role. The epitopes of the three antibodies require octa- and larger oligosaccharides, presenting one D-unit in the middle of the sequence; this implies the importance of the neighboring disaccharide units. The terminal flattened unsaturated uronic acid, which does not exist in natural CS or DS polymers, may mimic a possible

Table 4: Average Dihedral Angles Used To Build the Average Conformations Presented in Figures 4 and 5

\begin{tabular}{|c|c|c|c|c|c|c|c|c|c|c|c|c|c|c|}
\hline \multirow[b]{2}{*}{ octasaccharide } & \multicolumn{2}{|c|}{$8-7$} & \multicolumn{2}{|c|}{$7-6$} & \multicolumn{2}{|c|}{$6-5$} & \multicolumn{2}{|c|}{$5-4$} & \multicolumn{2}{|c|}{$4-3$} & \multicolumn{2}{|c|}{$3-2$} & \multicolumn{2}{|c|}{$2-1$} \\
\hline & $\varphi$ & $\psi$ & $\varphi$ & $\psi$ & $\varphi$ & $\psi$ & $\varphi$ & $\psi$ & $\varphi$ & $\psi$ & $\varphi$ & $\psi$ & $\varphi$ & $\psi$ \\
\hline$\Delta \mathrm{C}-\mathrm{A}-\mathrm{D}-\mathrm{C}$ & 275 & 105 & 270 & 220 & 280 & 110 & 280 & 230 & 275 & 105 & 270 & 220 & 275 & 105 \\
\hline$\Delta \mathrm{C}-\mathrm{A}-\mathrm{D}-\mathrm{A}$ & 275 & 105 & 270 & 220 & 280 & 110 & 280 & 230 & 275 & 105 & 270 & 220 & 280 & 110 \\
\hline$\Delta \mathrm{A}-\mathrm{A}-\mathrm{D}-\mathrm{C}$ & 280 & 100 & 270 & 230 & 280 & 110 & 280 & 230 & 275 & 105 & 270 & 220 & 275 & 105 \\
\hline$\Delta \mathrm{A}-\mathrm{A}-\mathrm{D}-\mathrm{A}$ & 280 & 100 & 270 & 230 & 280 & 110 & 280 & 230 & 275 & 105 & 270 & 220 & 280 & 110 \\
\hline$\Delta \mathrm{C}-\mathrm{C}-\mathrm{C}-\mathrm{C}$ & 275 & 105 & 270 & 220 & 275 & 105 & 270 & 220 & 275 & 105 & 270 & 220 & 275 & 105 \\
\hline
\end{tabular}


extended conformation of the larger epitope sequences in the parent polymers. Since such linear oligosaccharides display rather high flexibility, the antibody-bound conformation may be significantly different from the most populated one in solution. Nevertheless, the repartition of negative charges in space that has been characterized here is likely to be determinant for the antibody during the recognition process. The CS-56 epitope is strongly expressed in the postnatal mouse brain cerebral cortex, whereas the MO-225 epitope is found in other regions of mouse developing brain (16), and the 473HD epitope is highly present in the cerebellum of adult mouse (12).

Further studies should be focused now on the chemical synthesis of these oligosaccharides, so that crystallographic studies of the antibodies together with the synthesized carbohydrates can be started, which will lead to a deeper understanding of the epitope specificity of these antibodies.

\section{ACKNOWLEDGMENT}

We thank Dr. R. Wechselberger for expert help with the collection of NMR spectra.

\section{REFERENCES}

1. Oohira, A., Matsui, F., Tokita, Y., Yamauchi, S., and Aono, S. (2000) Molecular interactions of neural chondroitin sulfate proteoglycans in the brain development, Arch. Biochem. Biophys. 374, 24-34.

2. Sugahara, K., and Kitagawa, H. (2000) Recent advances in the study of the biosynthesis and functions of sulfated glycosaminoglycans, Curr. Opin. Struct. Biol. 10, 518-527.

3. Sugahara, K., Mikami, T., Uyama, T., Mizuguchi, S., Nomura, K., and Kitagawa, H. (2003) Recent advances in the structural biology of chondroitin sulfate and dermatan sulfate, Curr. Opin. Struct. Biol. 13, 612-620.

4. Matsui, F., Nishizuka, M., Yasuda, Y., Aono, S., Watanabe, E., and Oohira, A. (1998) Occurrence of a N-terminal proteolytic fragment of neurocan, not a C-terminal half, in a perineuronal net in the adult rat cerebrum, Brain Res. 790, 45-51.

5. Pizzorusso, T., Medini, P., Berardi, N., Chierzi, S., Fawcett, J. W., and Maffei, L. (2002) Reactivation of ocular dominance plasticity in the adult visual cortex, Science 298, 1248-1251.

6. Moon, L. D. F., Asher, R. A., Rhodes, K. E., and Fawcett, J. W. (2001) Regeneration of CNS axons back to their target following treatment of adult rat brain with chondroitinase $\mathrm{ABC}$, Nat. Neurosci. 4, 465-466.

7. Laabs, T., Carulli, D., Geller, H. M., and Fawcett, J. W. (2005) Chondroitin sulfate proteoglycans in neural development and regeneration, Curr. Opin. Neurobiol. 15, 116-120.

8. McKeon, R. J., Hoke, A., and Silver, J. (1995) Injury-induced proteoglycans inhibit the potential for laminin-mediated axon growth on astrocytic scars, Exp. Neurol. 136, 32-43.

9. Zuo, J., Neubacher, D., Dyess, K., Ferguson, T. A., and Muir, D. (1998) Degradation of chondroitin sulfate proteoglycan enhances the neurite-promoting potential of spinal cord tissue, Exp. Neurol. $154,654-662$.

10. Yamagata, T., Saito, H., Habuchi, O., and Suzuki, S. (1968) Purification and properties of bacterial chondroitinases and chondrosulfatases, J. Biol. Chem. 243, 1523-1535.

11. Faissner, A., Clement, A., Lochter, A., Streit, A., Mandl, C., and Schachner, M. (1994) Isolation of a neural chondroitin sulfate proteoglycan with neurite outgrowth promoting properties, J. Cell Biol. 126, 783-799.

12. Clement, A. M., Nadanaka, S., Masayama, K., Mandl, C., Sugahara, K., and Faissner, A. (1998) The DSD-1 carbohydrate epitope depends on sulfation, correlates with chondroitin sulfate D motifs, and is sufficient to promote neurite outgrowth, J. Biol. Chem. 273, 28444-28453.

13. Nadanaka, S., Clement, A., Masayama, K., Faissner, A., and Sugahara, K. (1998) Characteristic hexasaccharide sequences in octasaccharides derived from shark cartilage chondroitin sulfate
D with a neurite outgrowth promoting activity, J. Biol. Chem. 273, 3296-3307.

14. Avnur, Z., and Geiger, B. (1984) Immunocytochemical localization of native chondroitin-sulfate in tissues and cultured cells using specific monoclonal antibody, Cell 38, 811-822.

15. Yamagata, M., Kimata, K., Oike, Y., Tani, K., Maeda, N., Yoshida, K., Shimomura, Y., Yoneda, M., and Suzuki, S. (1987) A monoclonal antibody that specifically recognizes a glucuronic acid 2-sulfate-containing determinant in intact chondroitin sulfate chain, J. Biol. Chem. 262, 4146-4152.

16. Maeda, N., He, J., Yajima, Y., Mikami, T., Sugahara, K., and Yabe, T. (2003) Heterogeneity of the chondroitin sulfate portion of phosphacan/6B4 proteoglycan regulates its binding affinity for pleiotrophin/heparin binding growth-associated molecule, J. Biol. Chem. 278, 35805-35811.

17. Ito, Y., Hikino, M., Yajima, Y., Mikami, T., Sirko, S., von Holst, A., Faissner, A., Fukui, S., and Sugahara, K. (2005) Structural characterization of the epitopes of the monoclonal antibodies 473HD, CS-56, and MO-225 specific for chondroitin sulfate D-type using the oligosaccharide library, Glycobiology 15, 593603.

18. IUPAC-IUB Joint Commission on Biochemical Nomenclature (JCBN) (1983) Symbols for specifying the conformation of polysaccharide chains. Recommendations 1981, Eur. J. Biochem. $131,5-7$.

19. Vliegenthart, J. F. G., Dorland, L., and van Halbeek, H. (1983) High-resolution ${ }^{1} \mathrm{H}$-nuclear magnetic resonance spectroscopy as a tool in the structural analysis of carbohydrates related to glycoproteins, Adv. Carbohydr. Chem. Biochem. 41, 209-374.

20. Homans, S. W., Dwek, R. A., and Rademacher, T. W. (1987) Tertiary structure in N-linked oligosaccharides, Biochemistry 26, $6553-6560$.

21. Klein, R. A., Hartmann, R., Egge, H., Behr, T., and Fischer, W. (1996) The aqueous solution structure of a lipoteichoic acid from Streptococcus pneumoniae strain R6 containing 2,4-diamino-2,4,6trideoxy-galactose: evidence for conformational mobility of the galactopyranose ring, Carbohydr. Res. 281, 79-98.

22. Allinger, N. L., Yuh, Y. H., and Lii, J. H. (1989) Molecular mechanics. The MM3 force field for hydrocarbons, J. Am. Chem. Soc. $111,8551-8556$.

23. Allinger, N. L., Rahman, M., and Lii, J. H. (1990) A molecular mechanics force field (MM3) for alcohols and ethers, J. Am. Chem. Soc. 112, 8293-8307.

24. Allinger, N. L., Zhu, Z. Q. S., and Chen, K. (1992) Molecular mechanics (MM3) studies of carboxylic acids and esters, $J$. Am. Chem. Soc. 114, 6120-6133.

25. French, A. D., Rowland, R. S., and Allinger, N. L. (1990) Computer modeling of carbohydrate molecules, in ACS Symposium Series 430, pp 120-140, American Chemical Society, Washington, DC.

26. Lamba, D., Glover, S., Mackie, W., Rashid, A., Sheldrick, B., and Pérez, S. (1994) Insights into stereochemical features of sulfated carbohydrates: X-ray crystallographic and modeling investigations, Glycobiology 4, 151-163.

27. Rodríguez-Carvajal, M. A., Imberty, A., and Pérez, S. (2003) Conformational behavior of chondroitin and chondroitin sulfate in relation to their physical properties as inferred by molecular modeling, Biopolymers 69, 15-28.

28. Le Questel, J. Y., Cros, S., Mackie, W., and Pérez, S. (1995) Computer modeling of sulfated carbohydrates: applications to carrageenans, Int. J. Biol. Macromol. 17, 161-175.

29. Haxaire, K., Braccini, I., Milas, M., Rinaudo, M., and Pérez, S. (2000) Conformational behavior of hyaluronan in relation to its physical properties as probed by molecular modeling, Glycobiology 10, 587-594.

30. Almond, A., and Sheehan, J. (2000) Glycosaminoglycan conformation: do aqueous molecular dynamics simulations agree with x-ray fiber diffraction?, Glycobiology 10, 329-338.

31. Engelsen, S. B., Cros, S., Mackie, W., and Pérez, S. (1996) A molecular builder for carbohydrates: application to polysaccharides and complex carbohydrates, Biopolymers 39, 417-433.

32. Preusser, A. (1989) Algorithm 671: FARB-E-2D: fill area with bicubics on rectangles - a contour plot program, ACM Trans. Math. Software 15, 79-89.

33. Waldherr-Teschner, M., Goetze, T., Heiden, W., Knoblauch, M., Vollhardt, H., and Brickmann, J. (1992) MOLCAD-Computer aided visualization and manipulation of models in molecular science, in Advances in Scientific Visualization (Post, F. H., and Hin, A. J. S., Eds.) pp 58-67, Springer, Heidelberg. 
34. Imberty, A., Bettler, E., Karababa, M., Mazeau, K., Petrova, P., and Pérez, S. (1999) Building sugars: The sweet part of structural biology, in Perspectives in Structural Biology (Vijayan, M., Yathindra, N., and Kolaskar, A. S., Eds.) pp 392-409, Indian Academy of Sciences and Universities Press, Hyderabad, India.

35. Bock, K., and Duus, J. Ø. (1994) A conformational study of hydroxymethyl groups in carbohydrates investigated by ${ }^{1} \mathrm{H}-\mathrm{NMR}$ spectroscopy, J. Carbohydr. Chem. 13, 513-543.

36. Bao, X., Mikami, T., Yamada, S., Faissner, A., Muramatsu, T., and Sugahara, K. (2005) Heparin-binding growth factor, pleiotro- phin, mediates neuritogenic activity of embryonic pig brainderived chondroitin sulfate/dermatan sulfate hybrid chains, J. Biol. Chem. 280, 9180-9191.

37. Bao, X., Muramatsu, T., and Sugahara, K. (2005) Demonstration of the pleiotrophin-binding oligosaccharide sequences isolated from chondroitin sulfate/dermatan sulfate hybrid chains of embryonic pig brains, J. Biol. Chem. 280, 35318-35328.

BI061971F 